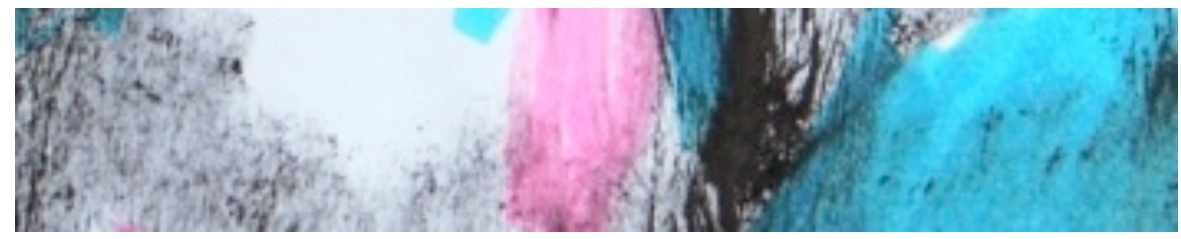

\title{
Telefones celulares, redes sociais e interacionismo simbólico: conexões possíveis
}

\section{Cell phones, social networks and symbolic interactionism: possible connections}

\author{
Renata Francisco Baldanza ${ }^{(*)}$ \\ Universidade Federal da Paraíba - Brasil \\ Universidade Federal da Bahia - Brasil \\ renatabaldanza@gmail.com \\ Nelsio Rodrigues de Abreu ${ }^{(* *)}$ \\ Universidade Federal da Paraíba - Brasil \\ nelsio@gmail.com
}

\section{Resumo \\ A emergência de novas tecnologias de comunicação faz com que as práticas sociais estejam em constante movimento $e$ adaptação à nova realidade comunicati- va. Deste modo, assim como as novas tecnologias são fruto da evolução tecno- lógica social, esta mesma sociedade as absorve e consequentemente alteram suas dinâmicas de interação e sociabilidade. A partir de tais pressupostos, apontamos}

\begin{abstract}
The emergence of new communication technologies makes social practices keep pace with the constant mobility and adaptation to the new communicative reality. Thus, as the new technologies are the result of socio-technological evolution, this same society absorbs them and constantly alters its dynamics of interaction and sociability. From these suppositions we can pinpoint a communicational
\end{abstract}


uma tecnologia comunicacional que indubitavelmente encontra nas sociedades contemporâneas o aporte necessário à sua permanência e aceitabilidade cada vez maior: os celulares. Tais artefatos atualmente deixam de ser apenas objeto de comunicação síncrona em tempo real pessoa-pessoa, para se transformar em um dispositivo híbrido e multifuncional, que ultrapassa sua funcionalidade prima e se torna uma das tecnologias digitais móveis mais utilizadas no planeta. Este artigo propõe um olhar sobre as relações entre tal artefato e o conceito de interacionismo simbólico amplamente discutido por Mead e Blumer, buscando uma reconfiguração do debate sob as nuances tecnológicas contemporâneas, em especial pelos telefones celulares.

Palavras-Chave: celulares, redes sociais, cibercultura, interacionismo simbólico. technology, which undoubtedly finds the necessary support in contemporary societies for its ever increasing permanence and acceptability: cell phones. Currently these artifacts are not only a synchronous person-to-person communication object in real time, but have transformed themselves into a hybrid and multifunctional device, which surpasses its main functionality and has become one of the most utilized mobile digital technologies on the planet. This paper proposes to take a look at the relationships between this artifact and the symbolic interactionism concept widely discussed by Mead and Blumer, to seek a reconfiguration of the debate about the contemporary technological nuances, especially cell phones.

Keywords: cell phones, social networks, cyberculture, symbolic interactionism. 


\section{INTRODUÇÃO}

A contemporaneidade faz emergir novas formas de comunicação que ultrapassam os formatos tradicionais dos últimos séculos. Paulatinamente, essas novas tecnologias de comunicação estão sustentando novas práticas que ao que parece, estarão onipresentes em muitos aspectos da vida contemporânea.

Dentre estas, destacamos os telefones celulares e as redes sociais onli$n e^{1}$ como alternativas interativas que compõem a sociedade na atualidade. Neste sentido, falar em comunicação mediada e em rede requer pensar na irreversibilidade deste processo, uma vez que já está enraizada nos grupos sociais. Assim sendo, este artigo ambiciona conduzir um primeiro olhar sobre as possíveis relações entre o conceito de interacionismo simbólico e o uso dos telefones celulares, bem como suas possibilidades como artefato potencializador das redes sociais online. Neste sentido, entendemos que este artefato poderá apoiar este processo de duas formas: primeiramente como interface para acesso à internet onde os interagentes poderão manter contato e atualizar suas páginas pessoais e também demais redes sociais as quais por ventura participem. Em segundo, e atualmente ainda mais utilizado que a primeira, o celular como ferramenta multifuncional que permite ao usuário captar imagens como fotos, gravar pequenos vídeos, ou arquivos de voz, que posteriormente serão baixados em um computador, e que alimentarão estas redes sociais.

Deste modo, entendemos que tal artefato maximiza os processos interativos a medida que auxilia nos pontos acima mencionados e, diante disso, tal relação entre celulares e redes sociais online poderão ser analisadas sob a ótica do interacionismo simbólico, a fim de verificarmos até que ponto é possível esta nuance.

1 Neste artigo, o termo "redes sociais online" será utilizado como forma de citar as redes de comunicação social mediadas, que necessitam de acesso à internet pois têm como ambiente de coexistência as plataformas da internet. Contudo, poderão ter como artefato de suporte para contato e acesso tanto os computadores, como telefones celulares, o que justifica o termo online.

Mediaciones Sociales, № 11, II semestre 2012, pp. 97-122. ISSN electrónico: 1989-0494. http://dx.doi.org/10.5209/rev_MESO.2012.v11.41271 


\section{INTERAÇÕES, REDES SOCIAIS E OS TELEFONES CELULARES: UM OLHAR TRANSVERSAL}

Quando falamos em interação mediada, podemos apontar dois enfoques cujo fenômeno pode ser analisado. $\mathrm{O}$ primeiro enfatiza aspectos relacionados à capacidade do artefato, de suas interfaces, bem como sua capacidade de processamento e usabilidade, ressaltando tais componentes técnicos como ponto importante na interação mediada, o que tenderia para o conceito de interatividade (Steuer apud Primo e Cassol, 2006; Lemos, 2007).

Lippman (1998), que traz reflexões sobre interação mediada e esteve na fronteira do estudo direcionado ao homem-máquina, posteriormente apresenta argumentos que o transfere para uma visão mais social deste fenômeno. Este seria um segundo enfoque o qual valoriza-se a comunicação contextualizada que ocorre entre interagentes e a evolução dos relacionamentos.

Partindo deste princípio, autores que aderem a esta linha ressaltam que, embora não se deva desconsiderar a capacidade da máquina neste tipo de comunicação, o aspecto fundamental no que se refere à interação neste caso, é a comunicação entre sujeitos, isto é, o artefato é apenas um meio o qual os sujeitos utilizam para se comunicar e interagir (Lippman, 1998). O mais importante aqui são as relações desenvolvidas por pessoas e a ênfase está na interação sujeito-sujeito. O artefato torna-se o meio (Primo e Cassol, 2006).

Lippman desvia seu interesse de investigação da máquina para as pessoas, e afirma que "em vez de trabalhar com a ideia de relacionamento entre homens e máquinas, considere pessoas com pessoas” (Lippman, 1998, online). Assim sendo, entendemos que da existência dos grupos sociais, surgem os processos comunicativos e a sociabilidade, que por sua vez tem como um de seus pilares a interação humana.

Como direcionamento neste trabalho, as duas premissas são passíveis de análise tendo em vista que: a) os telefones celulares por serem um dispositivo multifuncional e móvel, podem ser considerados um meio eficaz de fomento, suporte e acesso às redes sociais. Assim, o artefato aqui é considerado como algo importante no processo de sustento dessas práticas interativas e de comunicação e b) as pessoas, apesar da importância dos recursos dos telefones celulares, são a base das relações.

Mediaciones Sociales, № 11, II semestre 2012, pp. 97-122. ISSN electrónico: 1989-0494. http://dx.doi.org/10.5209/rev_MESO.2012.v11.41271 
Tais práticas interativas vêm se alterando ao longo do tempo, principalmente levando-se em conta a evolução tecnológica nos últimos 50 anos. De acordo com a figura a seguir (figura 1), verificamos uma evolução das principais formas de interação desde 1800 até uma projeção para 2015, que dá destaque às redes sociais na atualidade:

Figura 1: Interação entre pessoas de 1800 a 2020.)

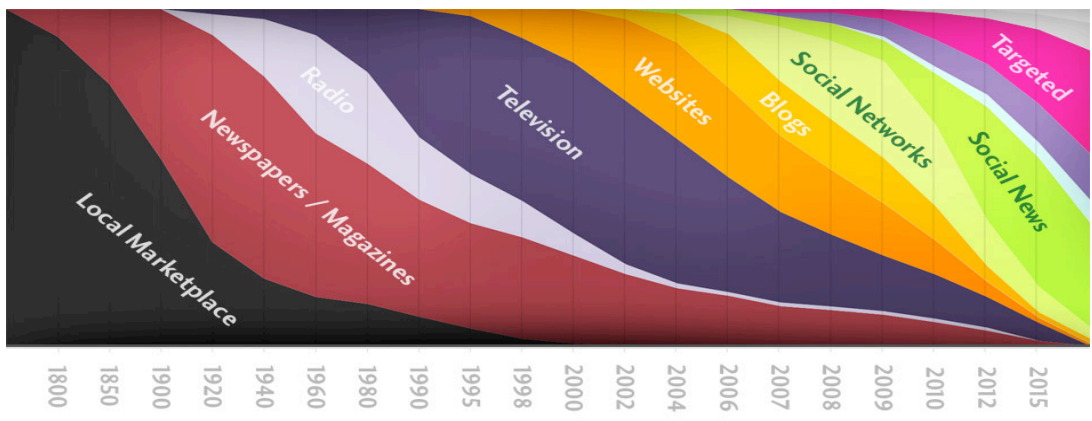

Fonte: Baekdal (2009)

No Brasil, este cenário parece seguir a mesma tendência. Uma pesquisa realizada pela ComScore entre dezembro de 2011 e janeiro de 2012 verificou que a rede social online Facebook ultrapassou o Orkut em número de usuários no país, alcançando 36 milhões de usuários únicos em dezembro de 2011. Embora o Orkut tenha alcançado um crescimento de $5 \%$ em 2011, manteve-se com 34 milhões de usuários únicos. Os dados sobre o Twitter foram os que mais se destacaram uma vez que em janeiro de 2012 o número de contas ultrapassou o Japão e posicionou o Brasil como segundo país a mais utilizar a rede — com 33 milhões de contas no Brasil- perdendo apenas para os Estados Unidos (COMSCORE, 2012).

Frente a isso, percebemos que o fenômeno das redes sociais online tende a se expandir por meio de outros artefatos que possibilitem seu acesso como os celulares, e assim sendo, torna-se fundamental compreender as relações de tais práticas com teorias consolidadas que possam embasar e explicar sob uma ótica interacionista, tais aspectos. Neste sentido, apresentamos reflexões que confrontem as práticas de interação em redes sociais online tendo como suporte os telefones celulares e os pressupostos do interacionismo simbólico. 


\section{Dispositivos Móveis de COMUNiCAÇÃO: EVOLUÇÃo E PERS- PECTIVAS}

As tecnologias de comunicação começaram a ser desenvolvidas pelo homem muito antes de se pensar num ambiente onde as pessoas poderiam interagir sem estarem ali. Sabemos que apesar do ciberespaço ter incitado debates sobre os processos contemporâneos de comunicação, algumas tecnologias de comunicação a distância como a carta, manuscritos dentre outros maximizados pelo aumento do letramento e de sua penetração na vida diária a partir do século XV, já sinalizavam a consolidação da comunicação mediada. Entretanto, a comunicação mediada em ampla escala somente foi possível a partir da prensa gráfica de Gutenberg e posteriormente do telégrafo, considerados pioneiros nesta modalidade. Ainda neste contexto, o ritmo de evolução dos processos de comunicação mediada ainda era irrisório, se comparados ao atual frenesi tecnológico que reflete na comunicação social.

Compreendemos que em um contexto de transformações graduais, a absorção de novos conhecimentos e tecnologias também se manifestará de forma gradual, como no momento da apresentação do primeiro telefone que foi recebido com incredulidade no século XX conforme resgatam Briggs e Burk (2004: 150-156): "em 1876, alguns sugeriram que "não havia necessidade de telefone; a sociedade sempre passou bem sem ele'. Esse tipo de crítica não era o único feito da época. O telefone frequentemente estava sob ataque".

Ironicamente, um dos artefatos que sofreram grande resistência há cerca de um século e meio atrás, atualmente em sua versão móvel (celular) não só está inserido em boa parte da população mundial, como também é um dos artefatos tecnológicos de comunicação de maior aceitabilidade e desejo da sociedade no país. Assim, acompanhando o ritmo acelerado das atuais inovações no campo das tecnologias e artefatos de comunicação, a sociedade se mostra cada vez mais suscetível a responder a tais mudanças no mesmo compasso. Ilustrando tais argumentos, de acordo com a Anatel ${ }^{2}$, em dezembro de 2011, em dados oficiais apresentados um seu relatório anual, o Brasil já contava com 242,2 milhões de aparelhos celulares ativos. As previsões para junho de 2012 ultrapassam os 245 milhões de aparelhos (ANATEL, 2011).

2 www.anatel.gov.br

Mediaciones Sociales, № 11, II semestre 2012, pp. 97-122. ISSN electrónico: 1989-0494. http://dx.doi.org/10.5209/rev_MESO.2012.v1 1.41271 
A telefonia móvel foi introduzida no Brasil em 1972, por um sistema anterior à tecnologia celular, um sistema de baixa capacidade, com tecnologia IMTS (Improved Mobile Telephone System). Em 1984, deu-se início à análise de sistemas de tecnologia celular sendo definido o padrão americano, analógico AMPS (Advanced Mobile Phone System ou Sistema de Comunicação de Telefonia Celular), como modelo a ser introduzido. Em 1990, o Rio de Janeiro é a primeira cidade brasileira a usar a Telefonia Móvel Celular e foi seguido por Campo Grande, Belo Horizonte e Goiânia. Em 1993 inaugurou-se a Telefonia Móvel Celular em São Paulo, e em novembro deste mesmo ano a Telesp Celular lança o seu celular digital. Em 1997, começa a operar o primeiro serviço celular digital da Banda B no Brasils.

Tais possibilidades no contexto brasileiro, na verdade, são fruto das inovações ocorridas com as tecnologias que posteriormente seriam adotadas nos celulares, nos anos 80 e 90. Na Europa nasceu o Global System for Mobile commnications (GSM), proposto em 1983, e que foi adotado pela maior parte dos países europeus como o "top" da comunicação digital móvel. Já nos EUA, duas tecnologias alternativas apareceram, o TDMA (Time Division Multiple Access) e o CDMA (Code Division Multiple Access). O TDMA e o GSM são tecnologias similares. Antes do desenvolvimento das tecnologias $3 \mathrm{G}$, foi desenvolvida uma tecnologia intermédia, denominada GPRS (General Packet Radio Service), designada por 2.5G, que não fazia mais do que utilizar canais TDMA partilhados para efetuar a transmissão de dados com o GSM (Coelho, 2006).

O CDMA é uma tecnologia que foi oriunda dos meios militares, muito mais adequada para comunicações de voz e dados que as outras, e como tal foi a base para o desenvolvimento de tecnologias móveis de terceira geração $(3 \mathrm{G})$ (Coelho, 2006). Portanto, a "Terceira Geração" da telefonia celular, nome dado às novas redes de banda larga móvel das operadoras, tem por objetivo oferecer acesso móvel à Internet em alta velocidade.

Para o futuro próximo estão previstas mais evoluções: o $\mathrm{O}$ 4G, quarta geração, permitirá débitos da ordem de 1 Gbps (100 Mbps em movimento). Pode-se contar também no futuro com a concorrência de tecnologias de

3 Informações expandidas em:

http://www.wirelessbrasil.org/wirelessbr/colaboradores/naiade/historia.html.

Mediaciones Sociales, № 11, II semestre 2012, pp. 97-122. ISSN electrónico: 1989-0494. http://dx.doi.org/10.5209/rev_MESO.2012.v1 1.41271 
tipo WiMAX (WorldWide Interoperability for Microwave Access), uma tecnologia Wireless que se destina a substituir o papel que as MAN (Metropolitan Area Networks) tiveram, e que poderá servir para interligar hotspots wi$f i$ (Coelho, 2006). Tal perspectiva vai de encontro com os preceitos citados por Pavlik (2008) quando afirma, por exemplo, que a direção futura das tecnologias de reprodução de imagens digitais refletem três tendências principais. Primeiramente, as tecnologias de reprodução de imagem estão em uma trajetória de miniaturização crescente. Segundo, dispositivos com design de fácil usabilidade e que continuam melhorando, especialmente para usuários sem treinamento avançado. Finalmente, e não necessariamente relacionado às duas tendências precedentes, cada vez mais, os dispositivos são capazes de funções múltiplas, características estas presentes em telefones celulares atuais, denominados por Lemos de Dispositivo Híbrido Móvel de Conexão Multirredes (DHMCM), minudenciando que

"o que chamamos de telefone celular é um Dispositivo (um artefato, uma tecnologia de comunicação); Híbrido, já que congrega funções de telefone, computador, máquina fotográfica, câmera de vídeo, processador de texto, GPS, entre outras; Móvel, isto é, portátil e conectado em mobilidade funcionando pó redes sem fio digitais, ou seja, de Conexão; e Multirredes, já que pode empregar diversas redes, como Bluetooth e infravermelho, para conexões de curto alcance entre outros" (Lemos, 2007: 2).

Desvencilhando-se de uma visão tecnicista sobre essas funções, acreditamos que essas e outras tecnologias que tais artefatos possuem, maximizam as práticas interativas em redes sociais móveis a medida que a partir de um celular, podemos não somente ter acesso às redes sociais online via internet do dispositivo e alimentá-las de algum modo, como por exemplo o envio em tempo real de uma imagem, um texto ou vídeo para um blog, streaming ${ }^{\star}$, mensagens curtas através de microblogs, serviços de localização e encontros, mas também utilizá-los de modo “off-line” para, por exemplo, captar imagens, sons e vídeos que poderão ser baixados no computador e posteriormente serem disponibilizados nas redes sociais online, ou até mesmo passados diretamente para outros dispositivos móveis que tenham tecnologias de compartilhamento como bluetooth, infravermelho, entre outros.

${ }^{4}$ Utilizado para distribuir e reproduzir conteúdos multimídia através da Internet. (http://pt.wikipedia.org/wiki/Streaming)

Mediaciones Sociales, № 11, II semestre 2012, pp. 97-122. ISSN electrónico: 1989-0494. http://dx.doi.org/10.5209/rev_MESO.2012.v11.41271 
Atualmente, a realidade brasileira pode ser considerada promissora em termos de telefonia móvel e acessibilidade à internet bem como às redes sociais via celulares. Em uma pesquisa divulgado pelo Grupo.Mobi ${ }^{5}$ em parceria com a agência digital W/McCann e IPSOS, onde foram entrevistados 1.000 homens e mulheres das classes $\mathrm{A}, \mathrm{B}$ e $\mathrm{C}$ residentes no Brasil, resultados projetam uma crescente acessibilidade móvel às redes sociais disponíveis na internet. De acordo com a pesquisa, $49,7 \%$ da classe A, 33,5\% da classe B e $19 \%$ da classe C possuem smartphones, o que retrata um número aproximado de 19 milhões dos usuários de telefonia móvel no Brasil. Dos usuários de smartphones, $83,1 \%$ acessam a internet via celular além dos 22,5\% de pesquisados que acessam-na por meio de telefones celulares convencionais. Em âmbito geral, dos pesquisados que costumam utilizar a internet via telefone celular, $83 \%$ afirmam acessar alguma rede social pelo aparelho. A pesquisa apontou ainda que $71,3 \%$ dos possuidores de celular com internet baixaram algum aplicativo de rede social e dentre elas, as mais apontadas como acessadas via celular são Orkut (49,4\%), Facebook (46,9\%) e twitter (36,6\%) (MOBI, 2011)

Outra observação a ser considerada são os dados da In-Stat, que prevê que até final de 2012 o número de usuários mundiais que acessarão redes sociais pelo celular chegará a 975 milhões, pouco além do número total de internautas do planeta atual (IDGNOW, 2009; Cervantes, 2009).

Sabe-se que a maioria das visitas a essas redes sociais online continua a ser feitas por pessoas sentadas diante de um computador, que contam aos amigos onde estão e como se sentem, trocam opiniões sobre filmes e músicas favoritos ou enviam vídeos (Reuters, 2009). Todavia, também acreditamos que os celulares podem contribuir com o sustento das redes sociais online uma vez que a partir dele, se pode criar arquivos de imagens, som ou vídeos, que poderão posteriormente ser baixados via computador e enviados às redes sociais online, o que o configura com tendo uma participação ativa neste processo interativo.

\footnotetext{
5 http://grupo.mobi/2012/
}

Mediaciones Sociales, № 11, II semestre 2012, pp. 97-122. ISSN electrónico: 1989-0494. http://dx.doi.org/10.5209/rev_MESO.2012.v11.41271 


\section{Contextualizando o interacionismo Simbólico}

A discussão sobre o interacionismo simbólico apresentada por Blumer (1969) e a concepção que sustenta uma de suas principais teorias, pressupõe os significados sociais como produtos, como criações que são formadas através da definição e das atividades de interação entre as pessoas. Sob este prisma, o significado das coisas é formado no contexto da interação social, é obtido e utilizado pelas pessoas a partir dessa interação.

Esta utilização de significados pelos atores, conforme termo utilizado por Blumer (1969) para designar as pessoas que interagem, ocorre através de um "processo de interpretação". Este processo tem duas fases distintas. Primeiro, o ator indica a si mesmo as coisas pelas quais ele está agindo, ele tem de chamar a atenção às coisas que têm significado para si mesmo. Em segundo lugar, por força deste processo de comunicação com ele, a interpretação se torna uma questão de manipulação de significados. O ator seleciona, verifica, suspende, reagrupa e transforma os significados à luz da situação em que ele é colocado e da direção da sua ação.

Para o autor, o termo "interacionismo simbólico" tem entrado em uso como um rótulo para uma abordagem distinta relativamente ao estudo da vida humana em grupo e conduta humana. Assim, o conceito de interacionismo simbólico é construído em torno destas conexões em geral. A partir daí ele aporta que o interacionismo simbólico repousa em última análise, em três simples premissas.

“A primeira premissa é que os seres humanos atuam nas coisas com base nos significados que essas coisas têm para eles. A segunda premissa é que o significado de tais coisas é derivado, ou decorre de uma interação social. A terceira premissa é que esses significados são manipulados, e modificado através de um processo interpretativo utilizado pela pessoa ao lidar com as coisas que ele encontra e criar um consenso" (Blumer, 1969: 2; grifo nosso).

A posição do interacionismo simbólico é, portanto, que os significados que as coisas têm para os seres humanos são centrais no seu próprio direito. Contornar o significado em favor dos fatores alegados para produzir o comportamento então, é visto como uma negligência grave ao papel do significado na formação do comportamento. 
É importante ressaltar que Blumer tem como ponto de partida cinco pontos que George Herbert Mead ${ }^{6}$ aponta em seu trabalho e que foram fundamentais à construção da ideia de Interacionismo Simbólico: o Self; a ação; a interação social; os objetos e as ações conjuntas. Quanto ao self, Mead (1967) interpreta o homem como sendo um ator que pode tanto interagir com os outros quanto consigo mesmo. Sobre a ação, o autor afirma que a mesma é desenvolvida num processo dinâmico para com o mundo ao invés de ser mera estrutura psicológica previamente existente ativada por fatores incidentes àquela estrutura. No que tange à interação social ele enfatiza uma diferenciação entre Interação Simbólica e Não-Simbólica. A primeira estaria permeada por símbolos, sendo, então, interpretada. A segunda alicerça-se na ideia de que podemos interpretar gestos que são puramente reflexivos e nos comportar de acordo com isso, não contendo simbologia. Em relação aos objetos Mead apud Blumer (1969) aponta que sua natureza é construída com base em sua significação, em seu sentido e sua significação depende de quem se refere a eles, isto é, todos os objetos são produções sociais. Por fim, as ações conjuntas seriam padrões de comportamento e interação entre os homens que coexistem no mesmo mundo, e são o foco principal do estudo do interacionismo simbólico por serem o mais fértil veículo para as transformações interpretativas causadas pelo processo de interação.

Deste modo, Blumer (1969: 8) discute sobre estas duas formas de interação social que são denominadas respectivamente "interação nãosimbólica" e "interação simbólica". Tais formas de interação possuem algumas características opostas, embora em sua essência, são ambas parecidas. A primeira ocorre quando se reage diretamente à ação de um outro sem que se interprete tal ação. Isso pode ser analisado como puro reflexo. A segunda por sua vez, implica interpretação dos atos, isto é, há uma carga simbólica muito grande e a interação vem repleta de significados e de subjetividade.

É a partir destes pressupostos que a abordagem do interacionismo simbólico surge no pensamento de Blumer. O interacionismo simbólico destaca que os seres humanos agem em relação ao mundo baseados no sentido que os mesmos conferem às coisas. Deste modo, este sentido é produzido através do processo de interação social. Berlo (1999) identifica

${ }^{6}$ Precursor dos pressupostos que embasaram o que viria a ser denominado posteriormente por Blumer (1969) de "Interaciosnismo Simbólico", conceito discutido no decorrer do artigo.

Mediaciones Sociales, № 11, II semestre 2012, pp. 97-122. ISSN electrónico: 1989-0494. http://dx.doi.org/10.5209/rev_MESO.2012.v11.41271 
que existe uma relação de interdependência na interação, onde cada agente depende do outro, ou seja, cada qual influencia o outro, mas alerta para a limitação em enxergar a interação apenas como ação e reação, isto é, as pessoas não funcionam da mesma forma e não se deve ter uma visão linear deste processo. Assim, seria impossível conceber a constituição do self fora da experiência social, apartada da interação entre indivíduos.

Refletindo sobre o self-uma das fontes de origem do pensamento blumeriano, Mead apud Blumer (1969), afirma que vê o ser humano como um organismo que cria sua relação para transformar o mundo, e dá um caráter único à sua ação. $\mathrm{O}$ ser humano pode considerar-se, têm concepções de si mesmo, comunica-se com ele, e age no sentido próprio. Estes tipos de comportamento implicam que o ser humano pode se tornar o objeto de sua própria ação. Esta auto-interação assume a forma do fazer indicações para si próprio, e satisfazer estas indicações para a confecção de mais indicações.

Aproximando-se a esta visão sobre interação, Gahagan traz reflexões sobre o processo de interação e inclusive argumenta em sua obra sobre a visão de Blumer. Gahagan (1980: 21) salienta que a conduta social é possibilitada pela comunicação, e reforça que "o homem, como sistema social, tem suficientes pontos biológicos em comum com outras espécies”. Porém sua interação com outros é um produto apenas de sua herança biológica. E a partir daí, evidenciase a importância da comunicação na interação social, fator que difere dos demais tipos de interação abordados em outras áreas do conhecimento.

O interacionismo simbólico baseia-se num número de ideias básicas ou “imagens origen”. Estas imagens descrevem a raiz e a natureza das seguintes questões: os grupos humanos ou sociedades, interação social, os objetos, o ser humano como um ator, a ação humana, bem como a interligação das linhas de ação, afirma Blumer (1969). Na percepção de Mead (1967), os seres humanos vivem em um mundo ou ambiente de objetos, e suas atividades são formadas em torno de objetos. Esta declaração se torna branda, e é muito significativa quando se percebe que, para Mead, os objetos são construções humanas e não entidades "auto-existentes" intrínsecas na natureza.

Deste modo, argumenta Mead apud Blumer (1969), existem vários pontos importantes na análise de objetos. Em primeiro lugar, a natureza de um objeto é constituída pelo significado que ela tem para a pessoa ou pessoas para quem é um objeto. Em segundo lugar, este significado não é 
intrínseco ao objeto, mas decorre da forma como a pessoa está inicialmente preparada para agir em relação a isso. Em terceiro lugar, os objetos, todos os objetos, são produtos sociais, na medida em que são formados e transformados pela definição dos processos que ocorrem na interação social.

A partir dos parâmetros iniciais de Mead, Blumer (1969) tenta trazer a tona uma gama de particularidades intrínsecas no interacionismo simbólico. Para o autor, na natureza da sociedade humana, os grupos humanos são vistos como sendo composto de pessoas que estão envolvidas na ação. A ação consiste nas atividades de toda espécie que os indivíduos realizam em sua vida, como eles encontram um ao outro e como eles lidam com as situações. Assim, os grupos de pessoas estão sempre entrando em co-ação. Para Blumer (1969), grupos de pessoas ou sociedades só existem "em ação" e dessa ação resultariam tanto a cultura que é derivada das coisas que as pessoas fazem, quanto a estrutura social que compõe-se dos relacionamentos e formas de como as pessoas agem com relação umas às outras.

Já em suas reflexões sobre a natureza da interação social, Blumer (1969: 7-8) salienta que as atividades de um indivíduo ocorreriam em resposta ou em relação às atividades de outro:

“a vida em grupo necessariamente pressupõe interação entre os membros do grupo, ou seja, a vida social consiste na interação dos indivíduos com as outras pessoas. $\mathrm{O}$ interacionismo simbólico não se limita a dar um caráter cerimonioso à interação social. Ele reconhece a interação social como sendo de vital importância para o seu próprio direito. Esta importância reside no fato de que a interação social é um processo que "faz a conduta humana", em vez de ser meramente um meio ou uma definição para a expressão ou liberação da conduta humana”. (Blumer 1969: 7-8).

Em seguida, reflete sobre a natureza dos objetos afirmando que a posição do interacionismo simbólico é de que os "mundos" que existem para os seres humanos e para os seus grupos são compostos de objetos e de que esses objetos são o produto da interação simbólica. Daqui resulta que, a fim de compreender a ação das pessoas, é necessário identificar seu "mundo de objetos". Estes objetos poderiam então ser físicos, sociais e abstratos. Sua natureza dependerá estritamente de quem interage com ele, pois não possuem status sólidos e variam com as indicações e definições que as pessoas fazem sobre eles.

Mediaciones Sociales, № 11, II semestre 2012, pp. 97-122. ISSN electrónico: 1989-0494. http://dx.doi.org/10.5209/rev_MESO.2012.v1 1.41271 
Blumer (1969) entende ainda que o ser humano age como um organismo. Assim, o interacionismo simbólico reconhece que os seres humanos devem ter uma composição que se ajusta à natureza da interação social. $\mathrm{O}$ ser humano é visto como um organismo que não só responde aos outros sobre o "não-simbólico", mas como um nível que torna a outras indicações e interpreta as suas indicações. A partir de tais pressupostos, ele argumenta que a capacidade do ser humano de fazer indicações para si mesmo dá um caráter distintivo à ação humana. Isso significa que a pessoa confronta um mundo que ele deve interpretar no sentido de agir em vez de um ambiente a que ele responde por causa de sua organização. Fundamentalmente, a ação por parte de um ser humano consiste em levar em conta várias coisas que ele observa e forjar uma linha de conduta a partir do modo de como ele as interpreta. Isso faria parte da natureza da ação humana, afirma (Blumer, 1969).

Por fim, destacamos que na percepção de Blumer (1969), a vida humana é constituída por grupos, e existem linhas de ação para si e para os membros do grupo. Essa articulação das linhas de ação dá origem e que constitui a "ação comum" —uma organização social de conduta de diversos atos de diversos participantes.

Uma “ação comum”, enquanto constituída por diversos componentes e atos que entram em sua formação, é diferente de qualquer um deles e de sua mera agregação. Vários comentários estão em ordem com relação a este claro regime. Em primeiro lugar, não se trata das extensões da vida em uma sociedade humana, em qualquer sociedade humana, mas é uma expressão pré-estabelecida de formas de ação conjunta. A segunda observação sobre a interligação que constitui uma ação conjunta refere-se à ligação de ação alargada que compõem a vida do grupo humano. A terceira importante observação precisa ser feita no sentido de que qualquer instância de uma ação conjunta, quer recém-formada ou estabelecida de longo prazo, necessariamente surge a partir de um fundo de ações anteriores dos atores (Blumer, 1969).

A partir das reflexões propostas pelos autores supracitados acerca do interacionismo simbólico, apresentamos algumas conexões entre a teoria em questão e as práticas de interação social através de redes sociais online, podendo ter como suporte os celulares.

Mediaciones Sociales, № 11, II semestre 2012, pp. 97-122. ISSN electrónico: 1989-0494. http://dx.doi.org/10.5209/rev_MESO.2012.v1 1.41271 


\section{Telefones CELUlares, RedeS E O INTERACIONISMO SIMBÓlI- CO: ASPECTOS RELACIONAIS}

Muitos dos conceitos e pensamentos abordados sobre interação social não enfocam ou mesmo não fazem menção à interação mediada, onde os aparatos de comunicação eram bem restritos, diferentemente dos estudos contemporâneos, que evidenciam mais este processo até mesmo por contar com tecnologias de comunicação cada vez mais utilizadas pelos indivíduos.

Apesar de sabermos da existência da interação mediada antes mesmo do advento da internet, as teorias mais antigas não enfatizam esta modalidade. Contudo, percebemos que algumas das teorias sobre interação social de adaptam sobremaneira às atuais formas de interação mediada. Assim sendo, entendemos que muitos dos argumentos que sustentam os preceitos do interacionismo simbólico podem ser encontrados nas interações mediadas.

Embora a interação mediada por artefatos digitais possa apresentar particularidades em relação à interação face-a-face, ressalta Santos (2002: 102), "seu ponto de partida analítico ainda é a interação não-mediada", ou seja, parte considerável dos problemas presentes na interação presencial é também encontrada na interação mediada. Portanto, acreditamos ser possível conectar em muitos aspectos, pressupostos do interacionismo simbólico que foram analisado sob a ótica da interação não-mediada de maneira geral, às práticas mediadas possibilitadas por meios e artefatos de comunicação contemporânea como os telefones celulares e as possibilidades de contato que ele proporciona, como o acesso às redes sociais online.

De acordo com o site O Globo (2009), entre os usuários de redes sociais, 69\% usam ferramentas como Facebook e MySpace para interagir com amigos e familiares, $65 \%$ trocam mensagens com parentes distantes, $47 \%$ tentam localizar amigos que perderam contato, e tudo isso já pode ser feito hoje via telefone celular. Um dado importante levantado em uma pesquisa realizada pelo Ibope Net/Ratings nas principais redes sociais como o Orkut ${ }^{7}$, que ainda é uma das redes mais acessadas pelos brasileiros, aponta que apesar do perfil do usuário das redes estar se alterando, a maio-

7 www.orkut.com.br

Mediaciones Sociales, № 11, II semestre 2012, pp. 97-122. ISSN electrónico: 1989-0494. http://dx.doi.org/10.5209/rev_MESO.2012.v1 1.41271 
ria ainda encontra-se na faixa dos 18 aos 25 anos (IBOPE, 2010). Consideramos este dado muito pertinente uma vez que sabe-se que o universo simbólico dos jovens é muito evidente e de extrema importância para seu desenvolvimento enquanto indivíduo social. Por isso, vinculamos este aspecto aos argumentos apresentados a seguir.

Quanto ao interacionismo simbólico, um dos primeiros pontos o qual chamamos atenção é quanto ao "processo de interpretação", que constituise de duas fases. Neste sentido acreditamos que a interação em redes sociais online por meio de celulares se encaixa nesta ótica uma vez que o interagente somente irá utilizar-se deste artefato para interagir em rede se o mesmo tiver significado para si mesmo, bem como as próprias práticas interativas que sustentam as redes sociais em questão. É importante ressaltar que tanto os telefones celulares quanto as redes sociais online atualmente constituem bem mais que um artefato e um ambiente para comunicação mediada. Neste sentido, sabe-se que estão carregados de simbologia. Assim, ter um telefone celular representa também a ideia de manter o status quo, ao passo que pertencer e interagir em uma rede social online significa "pertencimento" a um grupo, aspecto discutido por Mafesolli (1985; 2006). Tais premissas estão presentes no universo dos jovens, que são a maioria nas redes sociais online. Essa junção da possibilidade de interagir em tempo real e em mobilidade na web via celular, torna-se então um dos formatos da interação contemporânea.

A partir das premissas discutidas por Blumer (1969), e tendo como base Mead, sabemos que os indivíduos atuam nas coisas "com base no significado que as mesmas têm para eles”, e assim sendo, a utilização dos celulares só se maximiza a medida que o interagente percebe que tal artefato ultrapassa a simples função de conversar. Ele torna-se então um objeto multifuncional cujas funções se tornam "muito importantes" ao seu possuidor. A questão do status trabalhado por diversos autores que estudam as práticas de interação via telefone celular e suas influências na sociedade e nos grupos como Levinson (2005) e Ling (2004) apontam para a percepção do público mais jovem para o fato dos mesmos enxergarem o telefone celular como fundamental para a sua sociabilidade na atualidade. Ações como troca e envio de mensagens para suas redes sociais - aqui apontamos não somente as redes sociais online disponibilizadas em plataformas na internet como também as redes sociais dos usuários oriundas do seu cotidiano social presencial, mas que interagem via telefone celular, troca e compartil- 
hamento de arquivos como fotos e vídeos, muitas vezes disponibilizados por meio de suas páginas pessoas em redes sociais na internet ou mesmo por meio de tecnologias disponíveis no celular que não dependem da internet, mas que permitem tal ação como bluetooth ou infravermelho. Possuir um telefone celular então atualmente pode significar ter o poder de comunicar-se, maximizar suas redes de contato — sejam elas online ou presenciais, de sociabilizar-se.

Somente para complementar, a maioria das pessoas que compra celulares se preocupa hoje com a existência te tais funções, mesmo que não utilizem todas elas, ou seja, possuir um celular que me permita, por exemplo, tirar fotos, utilizar mensagens SMS e acessar a internet, é importante muitas vezes pelo seu significado, mas não necessariamente pelo uso contínuo destes recursos.

Outra premissa abordada se refere ao fato de que "este significado decorre de uma interação social”, que hoje podemos observar quando observamos que um artefato como um aparelho celular ou uma prática - como pertencer a uma rede social e a partir daí ter contato com muitos "amigos", só se torna importante a medida que eu percebo que tais pontos são importantes para todo o grupo, ou para a sociedade a qual o indivíduo encontrase inserido. Indagamos: se as pessoas do meu grupo não atribuíssem valor às redes sociais online e aos celulares, eu atribuiria? Muito provavelmente não, ou não com tanta intensidade. Isso só ocorre por que através da interação o indivíduo percebe a importância disso para o conjunto, configurando-se como um processo mútuo. Portanto, possuir um artefato que permita esta troca que aos olhos dos indivíduos e também de seus grupos faz parte do processo de sociabilidade, interação e consequentemente integração dos mesmos, torna-o, além de um objeto, de algo simbólico para os envolvidos.

Por fim, abordando a última premissa que relata que "tais significados são manipulados e modificados de acordo com seu próprio universo simbólico", argumentamos que da mesma forma acontece atualmente com o uso de telefones celulares como meio para fomento das redes sociais online. Isso pode ser facilmente constatado quando ilustramos tais práticas entre jovens e adultos. Conforme mencionado acima, a maioria dos que compõe tal ambiente são de adolescentes e jovens adultos, e neste sentido, percebemos que os mesmos atribuem maior importância ao fato de estarem na internet

Mediaciones Sociales, № 11, II semestre 2012, pp. 97-122. ISSN electrónico: 1989-0494. http://dx.doi.org/10.5209/rev_MESO.2012.v1 1.41271 
interagindo com seu grupo social, ou seus grupos sociais. Isso provavelmente está ligado ao sentimento de pertencimento e criação de identidade, aspectos esses que talvez sejam menos importantes a adultos com mais de 25 anos, uma vez que já se fortaleceram enquanto ser social. Por estes aspectos e dados acima mencionados, a posse deste artefato bem como seu uso para interação em redes online tende a ser mais eminente nos jovens do que em pessoas mais velhas, o que ratifica a ideia de que seu universo simbólico ajuda a determinar seus padrões de interação.

Outros aspectos que merecem destaque nas reflexões sobre interacionismo simbólico são os cinco pontos que Blumer (1969) apresenta embasando-se em Mead (1967). Estes também podem ser verificados na relação entre o uso dos telefones celulares e redes sociais na atualidade.

Em relação ao "self”, entendemos que o indivíduo, a partir de seu universo, cria suas relações com o mundo, e neste sentido, analisamos mais uma vez a enorme presença nas redes sociais online, onde este self é expresso a partir de páginas pessoais cujas informações e perfil será acessado pelos demais que compõe esta rede. $\mathrm{O}$ celular neste momento entrará como suporte onde sua multifuncionalidade permitirá, por exemplo, captar imagens de viagens e momentos individuais cujo ator deseja compartilhar com os demais como forma de externalizar seu “eu”. A partir desta página individual, o indivíduo passa a compartilhar sua subjetividade com suas redes sociais online, o que poderia configurar a "ação" enquanto processo dinâmico para com o mundo, isto é, eu me desvencilho de uma estrutura interna psicológica para buscar compartilhamento e interação com grupos sociais.

Esta “interação social” por sua vez é dividida em dois tipos apontadas respectivamente como "interação simbólica” e “interação não-simbólica”. Nesta primeira, pressupõe-se uma carga maior de simbologia no processo interativo, e a interação possui grande significado, o que poderíamos perceber sem muitos esforços, nas dinâmicas interativas traçadas nas redes sociais online e por meio dos telefones celulares enquanto objeto potencializador das mesmas. É importante ressaltar ainda que mesmo em relação às demais redes sociais do indivíduo - aquelas que se formam em ambientes presenciais e que sustentam as relações cotidianas das pessoas, o telefone celular detém uma forte relação com os processos interativos na atualidade uma vez que têm maximizado o contato entre as pessoas por meio das ligações convencionais e fortalecendo laços em muitos casos.

Mediaciones Sociales, № 11, II semestre 2012, pp. 97-122. ISSN electrónico: 1989-0494. http://dx.doi.org/10.5209/rev_MESO.2012.v11.41271 
Esta última por sua vez, ocorre como uma reação direta e sem interpretação do ato. Neste sentido, não identificamos tais aspectos na relação entre o uso dos telefones celulares como dispositivo facilitador da alimentação de redes sociais online, uma vez que ao analisarmos seu uso como fomento à interação mediada na web, entendemos que isso vem carregado de significados. Até mesmo o simples recebimento de um SMS ao nosso entender muitas vezes denota subjetividade, principalmente no que tange ao público jovem, o que muitas vezes não se enquadraria nesta segunda opção. Talvez o ato de simplesmente atender a uma ligação poderia caracterizar este segundo tipo, mas não é nosso enfoque. Outro ponto a ser destacado neste momento é o fato de que endossamos a ideia da improbabilidade de uma interação totalmente isenta de significado, de subjetividade ou de atos interpretativos mínimos. Assim, talvez pudéssemos analisar a interação não-simbólica como sendo com uma carga simbólica menor, mas não nula.

No que tange aos "objetos", destacamos aí o próprio telefone celular enquanto artefato que tem seu significado construído a partir da ótica de sua produção social enquanto sentido. Sabemos que cada sociedade cria seus significados e cada objeto será mais ou menos valorizado, e seu valor será mensurado tendo como base uma grande carga simbólica e subjetiva. Isso obviamente está diretamente ligado à cultura local bem como os paradigmas sociais vigentes naquele contexto ou naquele momento. Para ilustrar tais argumentos, no caso do Brasil, o telefone celular só se popularizou a partir de 1998 com a privatização da até então estatal Telebrás, que detinha o monopólio das telecomunicações no país. A té então, os telefones celulares eram relativamente caros e de maneira geral, eram vistos como algo necessário apenas aos profissionais que necessitavam serem localizados a qualquer momento ou hora como médicos, advogados entre outros. A partir de 1998, operadores privadas de telefonia móvel começaram uma disputa acirrada por clientes e este fato fez com que não somente os preços dos telefones celulares decrescessem continuamente, como também os planos das operadoras para ligações, SMSs e atualmente internet, ficassem cada vez mais atrativos em termos de custo. Atualmente no Brasil, o preço médio de um SMS gira em torno de $\mathrm{R} \$ 0,33$ (trinta e três centavos), existem planos de chamadas pré-pagas em que o usuário paga o valor de $\mathrm{R} \$ 0,25$ (vinte e cinco centavos) pela chamada e temos internet para telefo- 
nes com planos pré-pagos a $\mathrm{R} \$ 0,50$ (cinquenta centavos) por dia ${ }^{8}$. Após tal expansão, tendo em vista que o país hoje possui mais celulares do que habitantes, a percepção da posse de tal artefato já não é mais a mesma se compararmos à vinte anos atrás. Em termos de status no que tange à posse de um celular pura e simplesmente, não é vista como algo mais tão significante no Brasil. Nosso contexto é um exemplo recente de como o valor simbólico atribuído a um objeto - no caso aqui, de uma tecnologia- se altera.

Contudo, outra questão para análise do objeto é a percepção do que possuir esse telefone celular representa enquanto facilitador da interação entre o indivíduo e suas redes. Neste sentido, a posse então passa a significar maior possibilidade de interação em tempo real e em mobilidade. Nesta direção, quando possuímos um artefato que nos permite maximizar relações sociais como interagir via páginas pessoais na internet com auxílio do celular, "twittar" para sua rede de contatos onde você se encontra, o que está acontecendo em seu bairro ou o que você está fazendo no momento, por exemplo, nossos vínculos sociais são facilitados pela tecnologia, principalmente em se tratando de redes, e neste contexto, a posse do objeto torna-se fundamental.

Na percepção de Mead (1967), os objetos são construções humanas e as atividades cotidianas são formadas em torno deles, e assim sendo, é o grupo como um todo que faz com que tanto os celulares quanto as redes sociais sejam tão importantes, e principalmente no caso particular dos telefones celulares, à exacerbada dependência do artefato, isto é, a dependência do "estar ali” disponível à interação. Complementando tais pensamentos destacamos Meyrowitz (1985: 5) quando realça que "o contato social não ganha significado apenas pela presença física e pelo lugar físico para interação, mas ganha significado a partir da mídia que utiliza”.

A “ação conjunta” por sua vez configura-se pelos padrões sociais que rumam ao consenso, e estão presentes sobremaneira nas interações mediadas e também nos objetos de nossa análise, uma vez que sabe-se que os aparelhos celulares já fazem parte do cotidiano social e tornam-se "subjetivamente indispensáveis”, ou seja, para a maioria das pessoas, sair sem um

8 Preços médios retirados da operadora Oi, TIM e Claro no ano de 2012. www.oi.com.br; www.tim.com.br; www.claro.com.br.

Mediaciones Sociales, № 11, II semestre 2012, pp. 97-122. ISSN electrónico: 1989-0494. http://dx.doi.org/10.5209/rev_MESO.2012.v11.41271 
celular significa deixar para traz uma parte importante de sua sociabilidade, assim como não estar inserido em uma rede social —estima-se hoje que mais de $90 \%$ dos internautas brasileiros estão inseridos em alguma rede social online (IBOPE, 2012). Esta ação conjunta irá configurar-se a partir da análise de quais ações o grupo absorve como sendo importante para sua integração e interação e como as mesmas são conduzidas, uma vez que uma das premissas da ideia de ação conjunta é justamente o conjunto de ações que compõem a vida do grupo. Em se tratando dos telefones celulares, hábitos como a troca de mensagens de texto entre adolescentes são tão enraizados em sua subcultura, que podem ilustrar este aspecto do interacionismo simbólico.

Blumer (1969) traz ainda a tona uma gama de norteamentos que giram em torno da natureza das coisas como, por exemplo, a natureza humana. Nesta direção, o autor reforça a ideia de que as sociedades só existem "em ação", aspecto este que fundamenta as redes sociais online uma vez que uma rede social online só existe se existirem pessoas que a movimentem e que a sustente enquanto ambiente de interação. Quanto à natureza da ação comum, que apresenta a ideia de que existem linhas de ação para si e para os outros, podemos aqui aproximar tais desígnios aos pensamentos de Goffman (1996). Para o autor em referência, o desempenho dos papeis sociais tem a ver com o modo como cada indivíduo concebe a sua imagem e a pretende manter. Assim, o homem em sociedade sempre utiliza formas de representações para se mostrar a seus semelhantes (Goffman, 1996). Tais padrões também são encontrados nas redes sociais online.

Deste modo, a partir de tais relações, entendemos que muitos dos aspectos levantados há mais de quatro décadas, num momento onde a comunicação mediada não abrangia mídias digitais que permitissem comunicação em rede de forma tão rápida e acessível, são aplicáveis às práticas interativas na atualidade, levando-nos a compreender a importância dos aspectos simbólicos nestas dinâmicas.

\section{Considerações FINAIS}

As redes sociais online configuram-se como microcosmos sociais, e muitas semelhanças são evidentes em relação às dinâmicas interativas presentes no cotidiano social de contato "presencial". Neste sentido, apreen-

Mediaciones Sociales, № 11, II semestre 2012, pp. 97-122. ISSN electrónico: 1989-0494. http://dx.doi.org/10.5209/rev_MESO.2012.v11.41271 
demos os telefones celulares como artefato potencializador das redes sociais online, pois dada à sua multifuncionalidade aliada à mobilidade e fácil manuseio, permitem às pessoas comunicarem-se no momento que desejar, em vários formatos. Assim sendo, o celular pode potencializar as redes sociais online a medida que possibilita vários níveis e formas de interação, tendo como suporte não somente seus próprios recursos (SMS, vídeochamada, câmera, etc.), mas também utilizando-se do ciberespaço concomitantemente ou não com tais recursos.

Os celulares hoje já são largamente utilizados como objeto que auxilia na alimentação das redes sociais online a medida que permite gravação de vídeo, captação de fotos e gravação de voz, cujos arquivos produzidos são muito utilizados nas redes. Assim, entendemos que mesmo que a utilização online dos telefones celulares —entenda-se uso das funções que necessitam da internet, ainda seja pequena no Brasil, eles se tornam uma ferramenta eficaz de suporte às redes sociais online, dando suporte às práticas de interação. Portanto, analisar estes processos sob a ótica do interacionismo simbólico nos ajuda compreender até que ponto devemos separar interação mediada e não-mediada, a não ser por um enfoque tecnicista.

Obviamente sem desconsiderar ainda o contexto brasileiro onde o acesso às redes sociais online via celular ainda é caro, sabemos que os celulares constituem uma das ferramentas potencialmente promissoras para efetivação da interação mediada em rede. Deixamos aqui portanto a discrepância no contexto brasileiro onde temos milhões de celulares ativos, milhões de pessoas nas redes sociais, e por motivos mercadológicos ainda não conseguimos unir com eficiência estes dois processos.

O que nos resta saber é se, e até que ponto essas diversas possibilidades podem afetar de algum modo os padrões de interação humana e quais possibilidades, alterações e capital que delas emergem. Mas o que podemos concluir no momento frente a estas reflexões é que os pressupostos do interacionismo simbólico, apesar de terem sido discutidos originalmente muito antes da existência massiva dos telefones celulares na sociedade, são altamente adaptáveis e adequados para se discutir os efeitos sociais das tecnologias e compreender as ações e mecanismos que são criados a partir do uso das mesmas no dia-a-dia das pessoas. 
Assim sendo, a conexão entre teorias difundidas sobre interação social e as atuais tecnologias que na prática possibilitam justamente isso, pode fazer avançar o debate acadêmico sobre como e em que medida se poderia pensar em analisar as práticas de comunicação móvel em rede sob a luz dos critérios de um paradigma clássico.

\section{Bibliografía}

ANATEL. Relatório Anual 2011 da Agência Nacional de Telecomunicações, disponível

http://www.anatel.gov.br/Portal/verificaDocumentos/documento.asp?numeroP ublica-

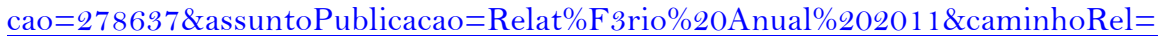
null\&filtro $=1 \&$ documentoPath $=278637 . \mathrm{pdf}$

Acesso em 20 de junho de 2012.

BAEKDal, T. (2009): “Where is everyone?”, New Madia Magazine, 27 de abril de 2009. Disponível em http://www.baekdal.com/analysis/market-of-information Acesso em 20 de agosto de 2010.

BerLo, D. (1999): O processo da comunicação. São Paulo: Martins Fontes.

Blumer, H. (1969): Symbolic interactionism, perspective and method. New Jersey: Prentice-Hall.

Briggs, A. y Burke, P. (2004): Uma história social da mídia. Rio de Janeiro: Jorge Zahar.

Cervantes, L. (2009): "Acesso a redes sociais pelo celular cresce $427 \%$ em um ano. "Sismoweb", Sismoweb/blog, 17 de marzo de 2009. Disponível em http://blog.sismoweb.com.br/wp-content/uploads/2009/03/internet_mobile.jpg Acesso em 03 de maio de 2009.

COMSCORE (2008): "Eighty Five Percent of Brazilian Internet Users Visited a Social Networking Site in September 2008", ComScore.com, septiembre de 2008. Disponível em http://bit.ly/WzoQmD

Acesso em 26 de maio de 2009. 
COMSCORE (2012): "Atividade nas Redes Sociais Aumentou no Brasil Ano Passado Impulsionada pelo Crescimento do Facebook", ComScore.com, 19 de marzo de 2012. Disponível em http://bit.ly/GIPwb5

Acesso em 19 de junho de 2012.

FERREIRA. P. H. (2005): "Notícias no celular: uma introdução ao tema. Dissertação (Mestrado em Ciências da Comunicação)". Universidade de São Paulo, 164 f. Disponível em http://bit.ly/SYyJwr

Acesso em 24 de janeiro de 2013.

GaHagan, J. (1980): Comportamento interpessoal e de grupo. Rio de Janeiro: Zahar.

Goffman, E. (1996): A representação do eu na vida cotidiana. Rio de janeiro: Vozes.

IBOPE, NetRatings (2010): "Informações detalhadas sobre as atividades dos internautas: Nível 2", Ibope.com.br, 2010. Disponível em http://www.ibope.com.br Acesso em 12 de novembro de 2010.

Lemos, A. (2007): "Comunicação e práticas sociais no espaço urbano: as características dos Dispositivos Híbridos Móveis de Conexão Multirredes (DHCMC)”, Comunicação, Mídia e Consumo, $\mathrm{n}^{\circ}$ 10, São Paulo.

Levinson, P. (2005): Cellphone: The story of the world's most mobile médium and how it has transformed everything! New York: Palgrave MacMillan.

LING, R. (2004): The mobile connection: the cell phone's impact on society. San Francisco: Elsevier.

Lippman, A. (1998): "O arquiteto do futuro”, Meio $\&$ Mensagem, São Paulo, n. 792, enero de 1998. Disponível em http://www.meioemensagem.com.br

Acesso em 30 de março de 1998.

Lourenzatto, C. R. P. (2004): "Serviços móveis e os impactos do novo modelo do setor de telecomunicações na sociedade brasileira”, dissertação (Mestrado em Engenharia Elétrica). Universidade de Brasília, 2004, 121 f. Disponível em http://www.sinagencias.org.br/conteudo_arquivo/120707_BBE8D7.pdf

Acesso em 24 de janeiro de 2013.

Maffesoli, M. (1985): A sombra de Dionísio: contribuição a uma sociologia da orgia. Rio de Janeiro: Graal.

MAfFesoli, M. (2006): O tempo das tribos: o declínio do individualismo nas sociedades de massa. (4. ed.). Rio de Janeiro: Forense-Universitária.

Mediaciones Sociales, № 11, II semestre 2012, pp. 97-122. ISSN electrónico: 1989-0494. http://dx.doi.org/10.5209/rev_MESO.2012.v11.41271 
MEAD, G. H. (1967): Mind, self and society. Chicago: University of Chicago Press.

MOBI (2011): “1 a Pesquisa \#Mobilize - Consumidor móvel 2011”, Slideshare.net., 2011. Disponível em http://www.slideshare.net/WMcCannBR/consumidormvel-2011

Acesso em 19 de junio de 2012.

O GLOBO (2009): "Redes sociais terão 800 milhões de usuários até 2012”. Disponível em

http://extra.globo.com/noticias/saude-e-ciencia/redes-sociais-terao-800-

milhoes-de-usuarios-ate-2012-diz-estudo-245020.html

Acesso em 24 de janeiro de 2013.

PAVlik, J. V. (2008): Media in the digital age. New York: Columbia University Press.

Primo, A. F. T. y CASSOL, M. B. S. (1999): "Explorando o conceito de interatividade: definições e taxiomas". Disponível em http://bit.ly/11426RG

Acesso em 24 de janeiro de 2013.

REUTERS (2009): “As redes sociais nos celulares”, Reuters Brasil, 2006. Disponível em http://br.reuters.com/news/internet

Acesso em 26 de maio de 2009.

SANTOS, H. (2002): "Interação social e novas mídias: elementos para uma análise da interação mediada”, Revista Famecos, n 18, p. 99-105, ago./nov. 


\section{PARA CITAR ESTE TRABAJO EN BIBLIOGRAFÍAS:}

BALDANZA, Renata Francisco y ABREU, Nelsio Rodrigues de (2012): "Telefones celulares, redes sociais e interacionismo simbólico: conexões possíveis", Mediaciones Sociales. Revista de Ciencias Sociales y de la Comunicación, $\mathrm{n}^{\circ}$ 11, pp. 97-122. DOI: http://dx.doi.org/10.5209/rev_MESO.2012.v11.41271

\section{Los autores}

(*) Doutoranda em Comunicação pela Universidade Federal da Bahia (UFBA) e Mestre em Comunicação pela Universidade do Estado do Rio de Janeiro (UERJ). Docente da Universidade Federal da Paraíba (UFPB) do Departamento de Administração. Atualmente realiza pesquisa nas áreas de Cibercultura, Tecnologias Móveis e Consumo. Líder do Grupo de Pesquisa em Consumo e Cibercultura (GPCiber/CNPq - UFPB) e Pesquisadora do Grupo de Pesquisa em Cibercidades (GPC - UFBA).

(**) Doutor em Administração pela Universidade Federal de Lavras (UFLA). Docente do Programa de Pós-Graduação em Administração e do Departamento de Administração (PPGA) da Universidade Federal da Paraíba (UFPB). Atualmente realiza pesquisas nas áreas de Consumo, Cibercultura, Comunicação Mercadológica. Líder do Grupo de Pesquisa em Consumo e Cibercultura (GPCiber/CNPq - UFPB).

RECIBIDO: 23 de noviembre de 2011.

ACEPTADO: 19 de julio de 2012. 